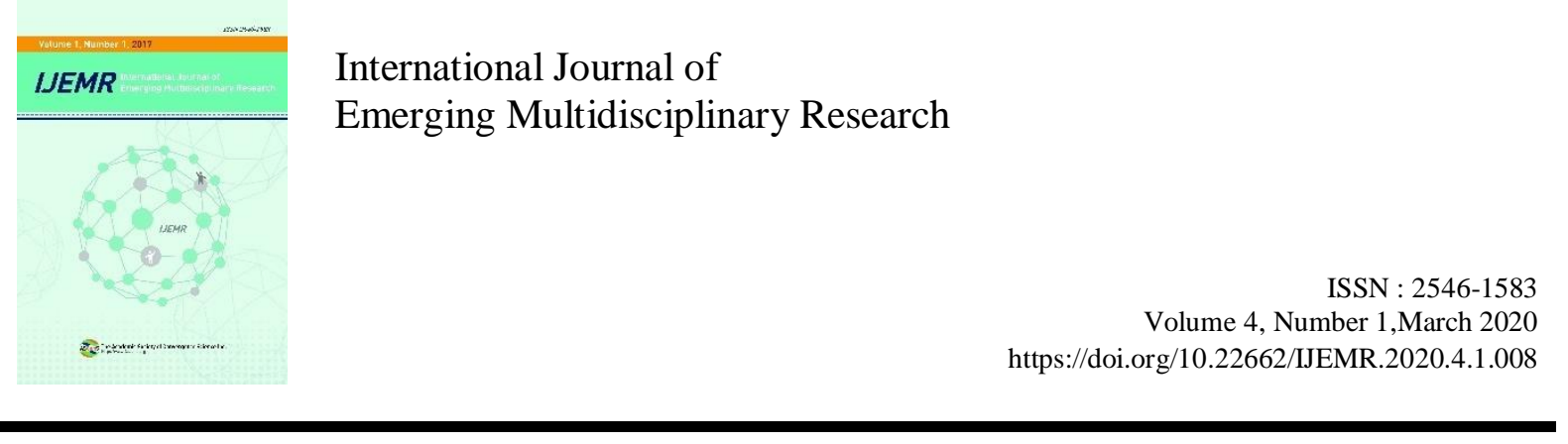

\title{
A Study on Motivation to Consumer Social Information Search
}

\author{
Hong Jin ${ }^{1}$, Guanghui Duan ${ }^{2}$, Seong-Taek Park ${ }^{3}$ \\ ${ }^{1}$ Guanghua School of Management,Peking University, Beijing, China; Jiangxi Normal University, China, \\ ${ }^{2}$ School of Business Jiangxi Normal University, China \\ ${ }^{3}$ MIS, Chungbuk National University, KOREA
}

\begin{abstract}
Background/Objectives: In this paper will explore consumers' motivation to search information in social media. This current work is of certain significance to enrich the theory of social information search and formulate marketing strategies. Methods/Statistical analysis: Through the literature review, this study summarizes the three motivations to consumer social information search: risk aversion motivation, entertainment motivation and social motivation. Findings: We will use structured interviews and empirical methods to further confirm the motivations of consumers' social information search. Improvements/Applications: This study is of certain significance to enrich the theory of social information search and to formulate targeted marketing strategies for enterprises.
\end{abstract}

\section{Index Terms}

Information Search, Social Media, Social Information Search

\footnotetext{
Corresponding author : Seong Taek Park

solpherd@cbnu.ac.kr

-Manuscript received January 10, 2020.

-Revised February 9, 2020; Accepted February 15, 2020.

-Date of publication March 31, 2020.

(1) The Academic Society of Convergence Science Inc.

2546-1583 @ 2017 IJEMR. Personal use is permitted, but republication/redistribution requires IJEMR permission.
} 


\section{INTRODUCTION}

With the rapid development of Internet technology, new Internet platforms such as social networking sites, social labeling system and social question-and-answer systems have emerged one after another. The traditional human-computer interaction mode is gradually being transformed into the humanto-human interaction mode[1].

Consumers are not only searchers and users of information, but also producers, disseminators and evaluators of information. Social media is gradually changing people's searching habits, more and more people like to use social media to search for the information they need.

The reason why users choose to search for information in social media is in essence that the information search in social media can meet their needs better. Consumers can strengthen their connections with others and obtain certain social capital through social information search, so as to improve their status in online communities.

Besides meeting the consumers' information needs, can social information search also meet consumers' social meetings?

Through literature review, risk aversion and entertainment motivation are the most important motivations for users to search in social media, but the deeper motivation still needs to be explored. The main difference between social information search and traditional information search lies in its sociality.

When users use their online social resources to search for information, they are actually interacting with them. Such interaction plays an important role in improving users' social status and acquiring online social resources.

Therefore, this paper will explore consumers' motivation to search information in social media. This current work is of certain significance to enrich the theory of social information search and formulate marketing strategies.

\section{LITERATURE REVIEW}

\section{A. Consumer social information search}

Information search is an important link before consumers make purchase decisions, and it helps consumers to reduce purchase risks[2].

Engel believes that consumer information search behavior is a process in which consumers extract knowledge stored in memory or obtain information from the external environment[3].

Solomon believes that consumer information search behavior is a process in which consumers obtain information from the external environment in order to make reasonable consumption decisions [4].

According to the information sources of consumers, consumer information can be divided into internal and external search. According to consumer search motivation, consumer information search behavior can be divided into pre-purchasing information search and on-going information search.

With the advent of the web2.0 era, the emergence of a large number of network platforms has led to rapid growth of user-generated content. By continuously generating, publishing, and sharing content on these network platforms, information has been efficiently and freely flowed between users and users. A new kind of information search model- social information search at the historic moment.

Freyne and Smyth put forward the concept of "social information search" for the first time. They found that members of the online community with the same interests are happy and able to quickly use search engines to get the information they need from content published by the community and other community members, and define the information search pattern for the socialization of information search.

In conclusion, we believe that consumer social information search refers to the process in which consumers use their social network resources to obtain information in social media.

\section{B. Research on motivation to social information search}

Based on the analysis of previous studies on consumer search information in social media, the motivations to consumer information search in social media are mainly divided into two categories: risk aversion motivation and entertainment motivation.

Risk aversion motivation is one of the most important motivations for information search. People need to search for information to solve problems in problem situations so as to avoid predictable risks[5].

In the context of Web2.0, users can easily interact with other users and obtain useful information through social media. Tourists search for tourist routes and scenic spots information from the social media, and patients search for health information in the social media to understand their own conditions; Consumers search for product and brand information in these platforms to make better consumption decisions.

Enjoyment is one of the main motivations for users to use social media. Information search is considered as an important dimension of users' community participation behavior, and information experience is also an important part of users' community experience[6].

Users do not always search for information in social media to solve problems, and sometimes it is just pure enjoyment. Previous studies have found that the entertainment factor can promote users to information search in social media[7].

There are few researches on the social motivation 
of users' social information search, but some scholars have explored the sociality of information search.

Some studies have found that relationship maintenance is an important influencing factor for users to participate in social network service, people will maintain their relationship with others through social information search[8].

Some studies have also found that social capital can enhance users' information search motivation in virtual communities[9].

\section{RESEARCH MODEL}

Based on previous research theories and results, this study initially establishes a research model of consumer social information search motivation, as shown in Fig. 1.

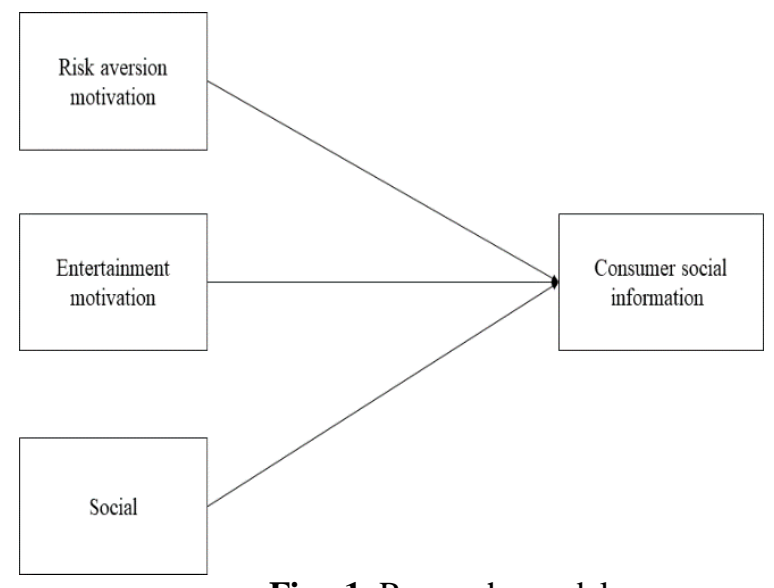

Fig. 1 Research model

H1. Risk aversion motivation will affect consumer social information.

H2. Entertainment motivation will affect consumer social information.

H3. Social will affect consumer social information.

\section{RESEARCH METHOD}

Later, this study will confirm the motivation of consumer social information search through structured interviews and empirical methods[10].

First, we will interview 36 consumers who have more than two years of experience in social media use, mainly asking consumers what information they search for in social media and why they search for it.

Then, we will design the questionnaire, the measured variables of the questionnaire are the motives for the consumer social information search, and the willingness to use social media to search for social information.

Finally, the SPSS software will be used to analyze the survey data and confirm the motivation to consumer social information search.

\section{CONCLUSION}

More and more consumers use social media to obtain the information they need. Understanding consumer social information search motivation is of great significance to understand the characteristics and rules of consumer information search. This research has certain significance to enrich the theory of social information search.

First of all, previous studies tend to focus only on consumers' pre-purchase information search, and pay less attention to consumers' continuous information search, which is ubiquitous in social media.

Secondly, consumers use social information search to connect with other consumers and maintain relationships with them.

However, previous studies only focused on the social information sharing of consumers and paid less attention to the significance of consumer social information search.

Finally, the research is of certain significance for enterprises to manage social media and formulate marketing strategies.

\section{ACKNOWLEDGMENT}

This study is supported by the China Postdoctoral Science Foundation(No.2017M 620532) and Jiangxi Universities Humanities and Social Sciences Research on Young Fund (GL17115).

\section{REFERENCES}

[1] Yang, J. L., Qin J. H., Wang L. Y., \& Lu, Y. Q. (2015). A survey of social information search research. Intelligence Theory and Practice, 38(3), 128-133.

[2] Solomon, M. R. (2008). Consumer behavior. Beijing: China Renmin University Press.

[3] Engel, J. F., Blackwell, R. D., \&Minard, P. W. (1986). Consumer behavior. Chicago: The Dryden Press.

[4] Vantzos, V. (2011). Consumer behavior: buying, having and being. Tourism Culture \& Communication, 11(2), 69-70.

[5] Dervin, \& Brenda. (1998). Sense-making theory and practice: an overview of user interests in knowledge seeking and use. Journal of Knowledge Management, 2(2), 36-46.

[6] Lin, K. Y., \& Lu, H. P. (2011). Why people use social networking sites: an empirical study integrating network externalities and motivation theory. Computers in Human Behavior, 27(3), 1152-1161.

[7] Wise, K., Alhabash, S., \& Park, H. (2010). Emotional responses during social information seeking on facebook. Cyberpsychology, Behavior, and Social Networking, 13(5), 555-562.

[8] Yin G. P., \& Cui J.H. (2013). Research on the use of incentive factors by social network service users-- 
based on the social perspective of $U \& G$ theory. Chinese Library Journal, 39(1), 51-62.

[9] Zhou, T., \& Lu, Y. B. (2008). Research on user participation behavior of mobile communities based on social capital theory. Management Science, 21(3), 4350.

[10] Hong Jin, Haiyan Wang, Seong-Taek Park, \& Young-Ki Kim (2018). Research on Marketing Strategy of Traditional Retailers under the Background of Internet--A Case Study of Wal-Mart. International Journal of Emerging Multidisciplinary Research, 2(3), 27-32. DOI: 10.22662/IJEMR.2018.2.3.027. 